\title{
Normal Threshold Size of Stimuli in Children Using a Game-Based Visual Field Test
}

\author{
Yanfang Wang · Zaria Ali · Siddharth Subramani · Susmito Biswas • \\ Cecilia Fenerty · David B. Henson · Tariq Aslam
}

Received: October 10, 2016 / Published online: November 24, 2016

(C) The Author(s) 2016. This article is published with open access at Springerlink.com

\section{ABSTRACT}

Introduction: The aim of this study was to demonstrate and explore the ability of novel game-based perimetry to establish normal visual field thresholds in children.

Methods: One hundred and eighteen children (aged $8.0 \pm 2.8$ years old) with no history of visual field loss or significant medical history

Enhanced content To view enhanced content for this article go to www.medengine.com/Redeem/3427F0602E $1 \mathrm{AD} 12 \mathrm{D}$.

Y. Wang · Z. Ali · S. Subramani · S. Biswas .

C. Fenerty · D. B. Henson · T. Aslam ( $₫)$

Manchester Royal Eye Hospital, CMFT, Manchester

Academic Health Sciences Centre, Oxford Road,

Manchester, UK

e-mail: Tariq.Aslam@cmft.nhs.uk

Y. Wang · C. Fenerty · D. B. Henson · T. Aslam Division of Pharmacy and Optometry, Faculty of Biology, Medicine and Health, University of Manchester, Manchester, UK

S. Biswas

Division of Evolution and Genomic Sciences, Faculty of Biology, Medicine and Health, University of Manchester, Manchester, UK

T. Aslam

Heriot Watt University, Edinburgh, UK were recruited. Each child had one eye tested using a game-based visual field test 'Caspar's

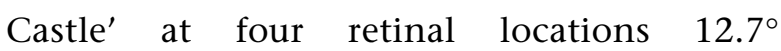
$(N=118)$ from fixation. Thresholds were established repeatedly using up/down staircase algorithms with stimuli of varying diameter (luminance $20 \mathrm{~cd} / \mathrm{m}^{2}$, duration $200 \mathrm{~ms}$, background luminance $10 \mathrm{~cd} / \mathrm{m}^{2}$ ). Relationships between threshold and age were determined along with measures of intra- and intersubject variability.

Results: The Game-based visual field test was able to establish threshold estimates in the full range of children tested. Threshold size reduced with increasing age in children. Intrasubject variability and intersubject variability were inversely related to age in children.

Conclusions: Normal visual field thresholds were established for specific locations in children using a novel game-based visual field test. These could be used as a foundation for developing a game-based perimetry screening test for children.

Keywords: Child health; Game-based test; Pediatrics; Perimetry; Visual field 


\section{INTRODUCTION}

Perimetry is an important instrument for diagnosing and measuring progression of neurologic diseases and glaucoma. However, in children decreased compliance associated with poor understanding of test procedures, difficulty with fixation [1], and short attention span can lead to limited reliability of conventional techniques [2].

There is evidence that attention and co-operation in young children can be improved with a more engaging central stimulus [3] such as a cartoon video or game [4-7], and several researchers have used this principle to develop visual field tests specifically for children [4, 5, 7-9]. Mutlukan and Damato [9] used a moving fixation target which the child had to track with the aid of a joystick. This technique reduced fixation losses but required good motor skills and focused the child's responses onto the fixation target rather than events occurring in the periphery. Murray et al. $[7,8]$ developed a test based upon eye movements. The test was easier for younger children who naturally wanted to look at any suddenly appearing stimulus but requires a calibration procedure and complex eye-tracking equipment. Allen et al. [4] used a preferential looking technique, in which an observer checked to see if the child moved their eyes in the correct direction when a cartoon video moved to a new location, but the technique is non-quantitative and may be only of value in detecting gross visual field defects.

For a perimetric technique to be sensitive to abnormalities, normal thresholds for that test need first to be known. The threshold is defined as the degree of intensity of a stimulus necessary to correctly detect that stimulus $50 \%$ of the time-a higher threshold relates to lower sensitivity to the stimulus by the patient. In routine perimetry, defect values are the difference between the age-corrected normal values and the threshold estimates, and probability values take into account their variability. With suprathreshold perimetry techniques a normal database is first needed to establish the appropriate intensities for each test location. As yet, however, there are limited studies exploring normal threshold levels in children and none using gamification techniques [1, 10-16].

For this paper we present a novel system of assessment of visual field thresholds for specific points in a child's visual field and explore the characteristics of such thresholds in different age groups. Obtaining separate thresholds for all possible test locations is not practicable as it would require extensive testing times that would even fatigue adults and lead to inappropriate values for children.

This paper therefore assesses detailed normative data for children at a selected eccentricity using a novel game-based visual field test 'Casper's Castle'. The current study does not represent validation of a field test but the application of new and novel technologies to explore and define threshold target sizes for children.

\section{METHODS}

\section{Subjects}

Ethical approval was obtained from the local National Health Trust committee and the study adhered to the tenets of the Declaration of Helsinki of 1964, as revised in 2013. Informed consent was obtained from all the adult participants or the guardian(s), and assent from children when possible (including the use of Fig. 1). Medical records of the children 


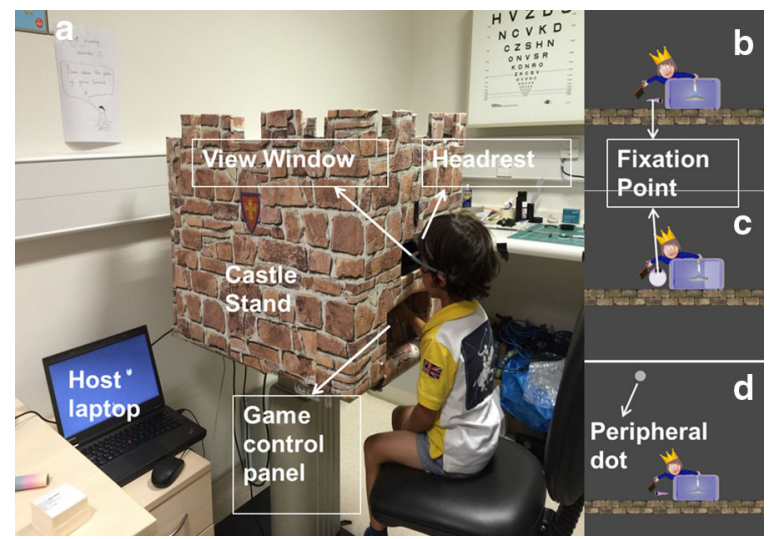

Fig. 1 Casper's Castle game-based visual field test for children (a). During the test, the participants were encouraged to look at the fixation point $(\mathbf{b}, \mathbf{c})$. They were instructed to press their control to get the Prince Casper to sweep the googlie up into the box when it became large (c) and to press their control to vacuum up any peripheral googlies (d) when they appear

were reviewed and the following inclusion criteria applied: children should be aged 4-15 years with no neurological/ocular diseases that could affect their visual field or physical pathology that would prevent them responding to a computer game. The age range reflects a desire to assess a broad range of children and the lower limit was set by pilot study experience that children aged under 4 years might have significant difficulty with the test. When both eyes met the inclusion criteria, one eye was randomly selected for testing. Any refractive errors were corrected before testing.

\section{The Perimeter}

The 'Caspar's Castle' perimeter is composed of a host laptop (Thinkpad, Lenovo, China) connected to a calibrated OLED display monitor (Sony PVM2541A, Sony Corporation, Japan) which is encased within a model castle structure. A viewing window and headrest in one wall of this structure allow for subjects to see the monitor, and a control panel connected to the host laptop allows them to respond to targets on the screen [5] (Fig. 1). The inside structure of the castle was covered with black felt to reduce reflections.

\section{Game Design and Test Strategy}

The game Caspar's Castle was programmed with Unity (version 4.3.4f1, Unity Technologies, San Francisco, USA) using the C\# language. Prior to playing the game, children were shown an animated storyline explaining the game plot. It involved a central character, Prince Caspar, with a vacuum cleaner and brush to sweep up 'googlies' that have 'messed up' the castle. A central googlie hovers just under the brush and the child was asked to sweep the googlie up when it became large by pressing a button (see Fig. 1). The central location of this googlie was taken to be the point of fixation from which the coordinates for the peripheral test stimuli were determined. A secondary task for the children was to press the button/move the joystick when a peripheral test target appeared, which children were told were extra escaped googlies. The game involved graphical awards and training levels before the threshold testing levels, which were programmed to increase in difficulty to match increasing competency of children playing the game.

Game design, prototyping, and development took account of game theories involving mechanics, esthetics, technology, and storyline [17]. These were considered along with psychological and specific psychophysical requirements of a perimetric test. The final physical and software game characteristics were derived by combining these fundamentals with an iterative approach of testing and redevelopment. In brief, in addition to regular software alterations, we explored the use of two 
operating systems, three programming languages, ten interactive model structures, five basic game types, and 12 types of input devices. After testing on an initial series of 112 patients, we felt from observational studies and patient/parent feedback that we had developed a satisfactorily working system. It is this final system that we present in this paper, used to assess normal thresholds in a further 118 children.

\section{Test Parameters}

In test period $1-3$, the luminance settings of the stimulus were $20 \mathrm{~cd} / \mathrm{m}^{2}$, background was $10 \mathrm{~cd} /$ $\mathrm{m}^{2}$, and the stimulus presentation time was $200 \mathrm{~ms}$.

The size of the test stimulus ranged from Goldmann size 0 to VII with seven extra intermediate levels (15 levels in total, Table 1).

\section{Threshold Algorithm}

An up/down staircase algorithm was used to determine the threshold size. The step size was set to two stimulus size levels until the first reversal and then reduced to one until the second reversal (terminating criterion) was reached. A pass criterion of two seen/three presentations was used for each size before any change was triggered. The last seen response was taken as the threshold estimate. To minimize long sequences of seen or not-seen responses two staircases were run simultaneously across all test locations, one starting from size 15 (well above the estimated threshold) and the other from size 1 (well below the estimated threshold). As soon as a terminating criterion had been reached a new staircase was started from the same starting

Table 1 Stimulus size levels in different units on the monitor (dimensions $54.4 \mathrm{~cm} \times 30.6 \mathrm{~cm}$, reference resolution $1920 \times 1080)$ at a viewing distance of $50 \mathrm{~cm}$

\begin{tabular}{llllc}
\hline $\begin{array}{l}\text { Stimulus } \\
\text { size level }\end{array}$ & $\begin{array}{l}\text { Goldmann } \\
\text { size level }\end{array}$ & $\begin{array}{l}\text { Angular } \\
\text { subtended }\left(^{\circ}\right)\end{array}$ & $\begin{array}{l}\text { Stimulus } \\
\text { diameter }(\mathbf{m m})\end{array}$ & $\begin{array}{l}\text { Stimulus } \\
\text { size (pixel) }\end{array}$ \\
\hline 1 & 0 & 0.05 & 0.47 & 1 \\
2 & & 0.08 & 0.67 & 2 \\
3 & I & 0.11 & 0.94 & 3 \\
4 & & 0.15 & 1.33 & 4 \\
5 & II & 0.22 & 1.88 & 6 \\
6 & & 0.31 & 2.66 & 9 \\
7 & III & 0.43 & 3.76 & 13 \\
8 & & 0.61 & 5.32 & 18 \\
9 & IV & 0.86 & 7.52 & 26 \\
10 & & 1.22 & 10.64 & 37 \\
11 & V & 1.73 & 15.05 & 53 \\
12 & & 2.44 & 21.28 & 75 \\
13 & VI & 3.45 & 30.10 & 106 \\
14 & & 4.88 & 42.56 & 150 \\
15 & VII & 6.89 & 60.20 & 212 \\
\hline
\end{tabular}


level. This process allowed collection of multiple threshold estimates if the subject was enjoying the game. The test was performed at an eccentricity of $12.7^{\circ}$ from fixation along the $45,135,225$, and $315^{\circ}$ meridians [18].

\section{Data Analysis}

All threshold estimates from the four test locations were pooled to provide both average values (final threshold for each subject) and a distribution of values (standard deviation, SD). Intersubject variability was calculated. Relationships between threshold, age, and intersubject variability were explored in Excel (Microsoft Office 2010, Microsoft, USA) and IBM SPSS Statistics (Version 22, IBM Corporation, USA).

\section{RESULTS}

One hundred and eighteen children participated in the study (mean age $8.0 \pm 2.8$ years, range $4.0-15.5$ years, 72 right eyes and 46 left eyes). There were no children with significant refractive error $(>4 \mathrm{D})$. Nineteen children $(16.1 \%$, aged $6.3 \pm 2.4$ years) stopped before the test end. Eleven children (9.3\%, aged $5.9 \pm 1.3$ years) failed to play the game and the data was lost from three participants (2.5\%) because of software errors. Eighty-five sets of data were available for analysis. The mean age of the children in the final data set was $8.7 \pm 2.7$ years, range $4.2-15.5$ years. The test time was $7.2 \pm 1.0 \mathrm{~min}(5.1-9.6 \mathrm{~min})$.

The threshold size at $12.7^{\circ}$ from fixation reduced steeply with age in children (Fig. 2). The intrasubject variability at $12.7^{\circ}$ from fixation was $1.1 \pm 1.1$ in children, range 0-6.4 levels $\left(0.26 \pm 0.25^{\circ}\right.$, range $\left.0.2-1.91^{\circ}\right)$. It was greater in children younger than 10 years old

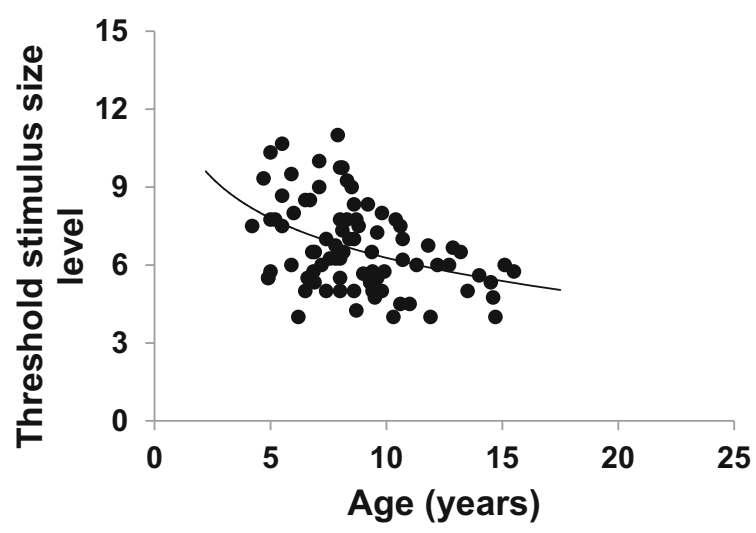

Fig. 2 Relationship between threshold size level and age in children

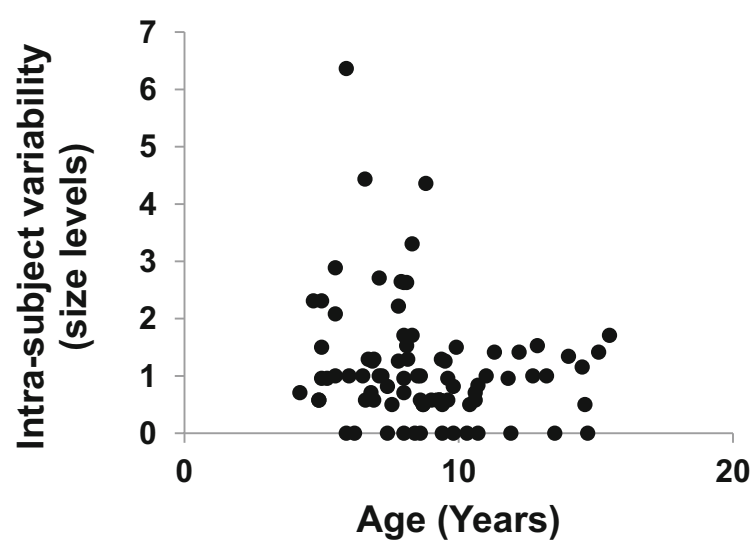

Fig. 3 Relationship between intrasubject variability and age in children

comparing to those over 10 years old (Fig. 3). The intersubject variability at $12.7^{\circ}$ from fixation in children was $1.7\left(0.52^{\circ}\right)$. It decreased significantly with age in children ( $p<0.001$, generalized linear model regression) (Fig. 4).

\section{DISCUSSION}

This study presents measurements of perimetric thresholds at a certain eccentricity for normally sighted children, using a purpose-built game-based visual field test. The system and software design, storyline, graphics, and game mechanics were optimized for good gameplay 


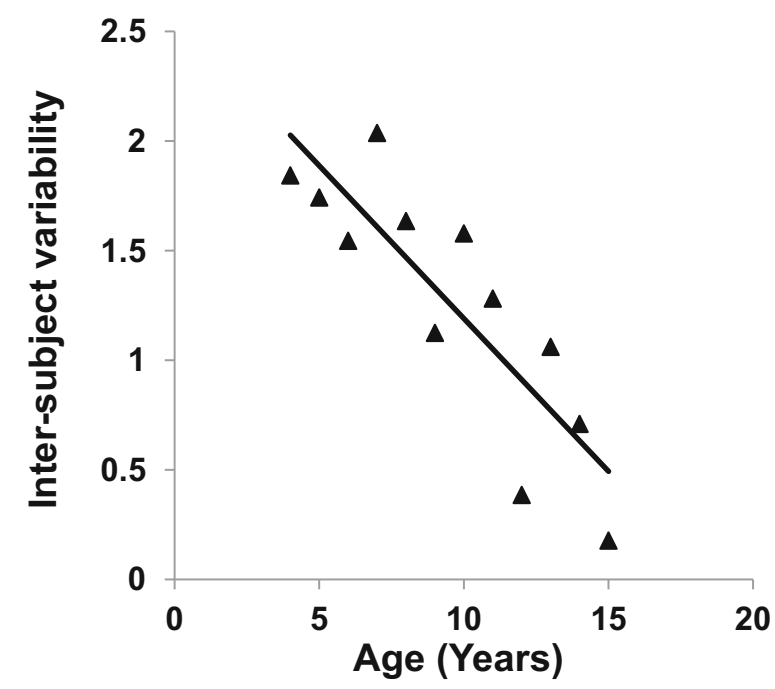

Fig. 4 Relationship between intersubject variability and age in children at eccentricity of $12.7^{\circ}$

and clinical objectives of maintaining central fixation with response to peripheral targets. This required a careful balance of game difficulties in order to minimize the effect of reduced spatial attention on peripheral stimuli [19].

In addition, the peripheral testing algorithms were purpose-built to assess visual field sensitivities in this difficult population. We derived thresholds using two fully automated and simultaneous staircases, one starting from above the estimated threshold and one from below, to reduce long sequences of seen/missed stimuli.

Children showed interest and enjoyment throughout the test. The test time was comparable to the time needed for a standard automated perimetric test in adults, and only a small percentage of children (16\%) did not complete it, testament to the power of the game-based test in maintaining the attention of children as young as 4 years old.

In this study, variable stimulus size was chosen in preference to variable stimulus intensity because of the luminance limitations of modern displays which can rarely exceed $300 \mathrm{~cd} / \mathrm{m}^{2}$.

The results from this study are consistent with those from other studies in finding a reduction in threshold (increased sensitivity) with increasing age $[11,14,16,20]$. Previous studies have indicated a linear increase of sensitivity with increasing age in children (up to 14 years) while some $[12,13,20]$ also reported that after a certain age (8-14 years) the association did not exist and the sensitivity was similar to young adults afterwards. Our study found the relationship of threshold with age was best fitted by a logarithmic rather than linear function. A similar finding was made by Blumenthal et al. [21] using frequency-doubling technology. This possibly reflects that the rate of development of the visual system is itself not linear. The decrease in variability with age was consistent with the earlier studies $[11,13]$.

Limitations of the study include the small sample size within individual age ranges and limited range of tested locations. Variations in children's ability to play computer games may have had an impact on variability as well as their psychophysical differences.

\section{CONCLUSION}

The current study demonstrates the potential of a game-based system, 'Caspar's Castle', to measure visual field thresholds in children. The results also provide detail on the nature of pediatric thresholds and variability with age in children. They could be used in future to derive approximate normative threshold values and suitable suprathreshold test intensities for clinical screening tests using the same game-based techniques. 


\section{ACKNOWLEDGEMENTS}

The work was presented at the 2016 annual meeting of the Association for Research in Vision and Ophthalmology, Seattle, USA, 1-5 May 2016.

The study was funded by the National Institute for Health Research in UK and facilitated by the Greater Manchester Local Clinical Research Network. The funding organization had no role in the design or conduct of the study; management, analysis, or interpretation of the data; preparation, review, or approval of the manuscript; and decision to submit the manuscript for publication.

All named authors meet the International Committee of Medical Journal Editors (ICMJE) criteria for authorship for this manuscript, take responsibility for the integrity of the work as a whole, and have given final approval for the version to be published.

We would like to acknowledge other collaborators for their substantial contributions: Terry Robinson (game programming); Savana Shakir, Tatianna Fernandes (data acquisition); Marco Miranda (earliest psychophysical set up).

Disclosures. Yanfang Wang, Zaria Ali, Siddharth Subramani, Susmito Biswas, Cecilia Fenerty, David B. Henson, and Tariq Aslam have nothing to disclose.

Compliance with Ethics Guidelines. Ethical approval was obtained from the local National Health Trust committee and the study adhered to the tenets of the Declaration of Helsinki of 1964, as revised in 2013. Informed consent was obtained from all the adult participants or the guardian(s), and assent from children when possible (including the use of Fig. 1).
Data Availability. The datasets during and/ or analyzed during the current study are available from the corresponding author on reasonable request.

Open Access. This article is distributed under the terms of the Creative Commons Attribution-NonCommercial 4.0 International License (http://creativecommons.org/licenses/ by-nc/4.0/), which permits any noncommercial use, distribution, and reproduction in any medium, provided you give appropriate credit to the original author(s) and the source, provide a link to the Creative Commons license, and indicate if changes were made.

\section{REFERENCES}

1. Bjerre A, Codina C, Griffiths H. Peripheral visual fields in children and young adults using semi-automated kinetic perimetry: feasibility of testing, normative data, and repeatability. Neuro-Ophthalmology. 2014;38:189-98.

2. Walters BC, Rahi JS, Cumberland PM. Perimetry in children: survey of current practices in the United Kingdom and Ireland. Ophthalmic Epidemiol. 2012;19:358-63.

3. Luna B, Velanova K, Geier CF. Development of eye-movement control. Brain Cogn. 2008;68:293-308.

4. Allen LE, Slater ME, Proffitt RV, Quarton E, Pelah A. A new perimeter using the preferential looking response to assess peripheral visual fields in young and developmentally delayed children. J Am Assoc Pediatric Ophthalmol Strabismus. 2012;16:261-5.

5. Aslam TM, Rahman W, Henson D, Khaw PT. A novel paediatric game-based visual-fields assessor. Br J Ophthalmol. 2011;95:921-4.

6. Gaggi O, Ciman M. The use of games to help children eyes testing. Multimed Tools Appl. 2016;75:3453-78.

7. Murray IC, Fleck BW, Brash HM, MacRae ME, Tan LL, Minns RA. Feasibility of saccadic vector optokinetic perimetry: a method of automated 
static perimetry for children using eye tracking. Ophthalmology. 2009;116:2017-26.

8. Murray I, Perperidis A, Brash $\mathrm{H}$, et al. Saccadic vector optokinetic perimetry (SVOP): a novel technique for automated static perimetry in children using eye tracking. Conf Proc IEEE Eng Med Biol Soc. 2013;3186-3189.

9. Mutlukan E, Damato BE. Computerised perimetry with moving and steady fixation in children. Eye. 1993;7:554-61.

10. Akar Y, Yilmaz A, Yucel I. Assessment of an effective visual field testing strategy for a normal pediatric population. Ophthalmologica. 2008;222:329-33.

11. Morales J, Brown SM. The feasibility of short automated static perimetry in children. Ophthalmology. 2001;108:157-62.

12. Patel DE, Cumberland PM, Walters BC, Russell-Eggitt I, Cortina-Borja M, Rahi JS. Study of optimal perimetric testing in children (OPTIC): normative visual field values in children. Ophthalmology. 2015;122:1711-7.

13. Tschopp C, Safran AB, Viviani P, Reicherts M, Bullinger A, Mermoud C. Automated visual field examination in children aged 5-8 years. Part II: normative values. Vision Res. 1998;38:2211-8.

14. Wabbels BK, Wilscher S. Feasibility and outcome of automated static perimetry in children using continuous light increment perimetry (CLIP) and fast threshold strategy. Acta Ophthalmol Scand. 2005;83:664-9.
15. Wilscher S, Wabbels B, Lorenz B. Feasibility and outcome of automated kinetic perimetry in children. Graefes Arch Clin Exp Ophthalmol. 2010;248:1493-500.

16. Wilson M, Quinn G, Dobson V, Breton M. Normative values for visual fields in 4- to 12-year-old children using kinetic perimetry/ normative values for visual fields in 4- to 12-year-old children using kinetic perimetry: discussion. J Pediatr Ophthalmol Strabismus. 1991;28:151-154.

17. Schell J. The art of game design: a book of lenses. Amsterdam: Elsevier/Morgan Kaufmann; 2008.

18. Henson DB, Artes PH. New developments in supra-threshold perimetry. Ophthalmic Physiol Opt. 2002;22:463-8.

19. Adam JJ, Davelaar EJ, Van Der Gouw A, Willems P. Evidence for attentional processing in spatial localization. Psychol Res. 2008;72:433-42.

20. Quinn LM, Gardiner SK, Wheeler DT, Newkirk M, Johnson CA. Frequency doubling technology perimetry in normal children. Am J Ophthalmol. 2006;142:983-9.

21. Blumenthal EZ, Haddad A, Horani A, Anteby I. The reliability of frequency-doubling perimetry in young children. Ophthalmology. 2004;111:435-9. 